\title{
Keseimbangan Kehidupan Kerja, Dukungan Sosial, dan Kesejahteraan Subjektif pada Guru Sekolah Luar Biasa (SLB)
}

\author{
Muhammad Allex Martadinata, Nina Zulida Situmorang, Fatwa Tentama \\ Program Studi Magister Sains Psikologi, Program Pascasarjana, Universitas Ahmad Dahlan, \\ Yogyakarta
}

Abstrak. Menghadapi Anak Berkebutuhan Khusus (ABK) merupakan sebuah tantangan tersendiri bagi seorang guru. Kompleksnya kondisi psikologis, seperti keterlambatan wicara, degradasi motorik dan kognitif pada ABK mengharuskan tenaga pendidik untuk lebih banyak mengatur regulasi serta mempertajam cara berpikir agar mampu mengondisikan ABK secara humanis. Penelitian ini bertujuan untuk mengetahui pengaruh keseimbangan kehidupan kerja dan dukungan sosial terhadap kesejahteraan subjektif guru di Sekolah Luar Biasa (SLB). Subjek dalam penelitian ini adalah 50 guru SLB dari jumlah populasi 144 guru. Teknik pengambilan sampel yang digunakan dalam penelitian ini adalah teknik simple random sampling. Instrumen yang digunakan adalah skala Kesejahteraan Subjektif, skala Keseimbangan Kehidupan Kerja, dan skala Dukungan Sosial. Teknik analisis data yang digunakan adalah analisis regresi linier berganda. Hasil analisis data menunjukkan rasio Fisher sebesar 36.734 dengan signifikansi sebesar $.000(p<.01)$ menunjukkan bahwa terdapat pengaruh yang signifikan antara keseimbangan kehidupan kerja dan dukungan sosial terhadap kesejahteraan subjektif pada guru SLB. Berdasarkan hasil penelitian dan pembahasan dapat dilihat bahwa terdapat pengaruh yang signifikan antara keseimbangan kehidupan kerja dan dukungan sosial terhadap kesejahteraan subjektif pada guru SLB.

Kata Kunci: dukungan sosial, guru SLB, keseimbangan kehidupan kerja, kesejahteraan subjektif

\section{Work Life Balance, Social Support, and Subjective Well-Being among Teachers in Special Needs' Schools}

Abstract. Teaching children with special needs is certaintly a challenge for teachers. The complexity of psychological conditions, such as emotional, speech delay, motor and cognitive degradation among children with special needs requires teacher to have more a better regulation and sharpen their mindset in order to be able to teach them humanistically. This study aimed to determine the effect of work-life balance and social support on subjective well-being. The subject of this study were 50 special school teachers (SLB) from a total of 144 teachers. And the sampling technique was a simple random sampling technique. In addition, The research instrument were Subjective Well-Being scale, Work-Life Balance scale, and Social Support scale. Data collected in this study was then analyzed using multiple linear regression analysis. The findings show that the Fisher's ratio was 36.734 with a significant value $.000(p<.01)$ indicating that there is a significant influence between work-life balance and social support for subjective well-being in special education school teachers. Furthermore, Based on the results of research and discussion, it can be seen that there is a significant influence between work-life balance and social support for subjective well-being in special education school teachers.

Keywords: social support, special education school teachers, subjective well-being, work-life balance

Korespondensi: Muhammad Allex Martadinata. Email: martadinata125x@gmail.com 
Menurut data Badan Pusat Statistik (BPS) tahun 2017, jumlah Anak Berkebutuhan Khusus (ABK) di Indonesia mencapai 1,6 juta jiwa. Jumlah tersebut semakin meningkat setiap tahunnya. Peningkatan ini menjadi catatan tersendiri bagi para guru, khususnya di Sekolah Luar Biasa (SLB) agar senantiasa meningkatkan kemampuan untuk memberikan pelayanan terbaik pada semua peserta didiknya. Hal ini tentu saja membutuhkan peran sekolah dan guru dalam memberi fasilitas pendidikan.

Profesionalitas seorang guru merupakan salah satu standar mutu dalam lingkup sekolah. Guru merupakan komponen penting yang dapat meningkatkan kualitas serta mutu pendidikan (Kurniawan et al., 2018). Berdasarkan Undang-Undang Republik Indonesia Nomor 14 Tahun 2005 tentang Guru dan Dosen, guru adalah pendidik profesional dengan tugas utama mendidik, membimbing, mengarahkan, melatih, menilai, dan mengevaluasi peserta didik pada pendidikan formal, pendidikan dasar, dan pendidikan menengah. Lebih khususnya, profesi guru SLB dengan tuntutan beragamnya kebutuhan khusus yang dimiliki peserta didik, akan berbeda dari guru sekolah biasa. Guru SLB seharusnya memiliki tingkat kesabaran yang lebih tinggi di saat memberikan instruksi pelajaran (Firmansyah \& Widuri, 2014). Menurut Efendi (2005), guru SLB juga seharusnya tidak hanya fokus pada materi, namun mereka juga dapat berperan menjadi konselor, pekerja sosial, terapis, paramedis, serta administrator (Agustin \& Afriyeni, 2016; Ardianingsih et al., 2017).

Guru SLB dituntut mengabdikan seluruh kemampuan, kreativitas, keterampilan, dan pikirannya untuk mendidik anak-anak luar biasa. Hal ini disebabkan karena anak-anak yang memiliki kebutuhan khusus, biasanya kurang responsif, menutup diri, bahkan menghindar dari orang lain, dihantui rasa malu, dan frustasi akibat kekhususan yang disandangnya. Tanpa memiliki dedikasi yang disertai kesabaran dan kreativitas dalam mengembangkan pendekatan pendidikan yang menarik, maka guru SLB akan gagal menjalankan tugasnya (Agustin \& Afriyeni, 2016; Supriadi, 2003). Selain memiliki banyak peran, guru SLB juga memiliki berbagai tugas yang harus dijalani, baik tugas yang terkait dengan dinas maupun luar dinas dalam bentuk pengabdian. Tugas guru tidak hanya sebagai profesi, tetapi juga sebagai suatu tugas kemanusiaan dan kemasyarakatan (Marsidi, 2007).

Individu yang sejahtera ditandai dengan adanya perasaan-perasaan positif yang muncul dalam kehidupan keseharian seorang individu. Kesejahteraan ditandai dengan tingginya kepuasan hidup dan kadar emosi positif serta rendahnya kadar emosi negatif (Carr, 2011). Hasil riset di kota Padang pada guru SLB terkait dengan kesejahteraan subjektif, disebutkan bahwa $100 \%$ responden masih memiliki kesejahteraan subjektif yang rendah (Agustin 
\& Afriyeni, 2016). Penelitian lain menjelaskan bahwa kesejahteraan subjektif guru SLB muncul pada afek negatif seperti rasa cemas, ragu-ragu, terkejut, dan tidak bersemangat sewaktu bekerja (Firmansyah \& Widuri, 2014). Dari kedua riset di atas, dapat disimpulkan bahwa guru SLB masih menunjukkan permasalahan pada kesejahteraan subjektif.

Guru SLB penting memiliki konsep keseimbangan kehidupan kerja agar mampu memiliki kesejahteraan subjektif yang tinggi. Hasil penelitian yang dilakukan oleh Association of Teachers and Lecturers (ATL) menyatakan bahwa terdapat 55\% guru yang mengatakan bahwa tekanan kerja memberikan efek yang merusak (detrimental) terhadap kesejahteraan (Hutapea \& Budiarto, 2016). Demi menghindari dampak negatif dari tantangan yang dihadapi, penting bagi guru SLB untuk dapat memaknai dan menilai proses yang dijalani sebagai suatu hal yang positif. Tantangan yang dihadapi oleh guru SLB dalam bekerja akan bermakna positif apabila mereka mampu menyeimbangkan antara tuntutan pekerjaan dan kebutuhan pribadi yang biasa disebut dengan keseimbangan kehidupan kerja (work life balance). Sebagaimana dikatakan oleh Westman et al. (2009) bahwa keseimbangan kehidupan kerja adalah sejauh mana individu terlibat dan sama-sama merasa puas dalam hal waktu. Selain itu, ditandai oleh keterlibatan psikologis dengan peran individu di dalam kehidupan kerja dan kehidupan pribadi (misalnya dengan pasangan, orang tua, keluarga, teman, dan anggota masyarakat), serta tidak adanya konflik di antara kedua peran tersebut.

Beberapa penelitian terdahulu telah membuktikan bahwa keseimbangan kehidupan kerja dapat menjadi faktor yang berpengaruh pada kesejahteraan subjektif (Brandstätter \& Opp, 2014; Cintantya \& Nurtjahjanti, 2018; Gröpel \& Kuhl, 2009; Jafri \& Batra, 2014; Pop, 2014). Dari beberapa penelitian tersebut, dapat disimpulkan bahwa individu yang mempersepsikan bahwa waktu mereka telah seimbang antara kehidupan dan kerja akan memengaruhi tingkat kesejahteraan subjektif yang lebih tinggi.

Beberapa penelitian menunjukkan bahwa dukungan sosial dapat memberi pengaruh pada kesejahteraan subjektif. Sarafino dan Smith (2011) mendefinisikan dukungan sosial sebagai perasaan nyaman, penghargaan, perhatian, atau bantuan yang diperoleh seseorang dari orang lain atau dari kelompoknya. Selain itu, Diener et al. (1999) menyatakan bahwa adanya dukungan sosial dan keintiman emosional dapat menciptakan relasi sosial yang positif. Hubungan yang di dalamnya terdapat dukungan dan keintiman akan membuat individu mampu mengembangkan harga diri, meminimalkan masalah-masalah psikologis, memiliki kemampuan memecahkan masalah, dan membuat individu tersebut menjadi sehat secara fisik. Penelitian terdahulu juga telah 
dilakukan, sehingga dapat dibuktikan bahwa dukungan sosial merupakan hal yang dapat memengaruhi kesejahteraan subjektif (Annink, 2017; Lutfiyah, 2017; Oftafia \& Susandari, 2019).

Terdapat beberapa penelitian dengan topik yang sama namun berbeda pada tujuan dan konteks subjek penelitian. Penelitian dengan analisis regresi yang mengungkapkan bahwa dukungan sosial dan ketidaklekatan (detachment) psikologis lingkup pekerjaan secara signifikan memoderasi hubungan antara keseimbangan kehidupan kerja dan kesejahteraan subjektif para dosen dan profesor di Bhutan (Jafri \& Batra, 2014). Penelitian lain memeriksa peran dua jenis dukungan keluarga, yaitu dukungan emosional dan instrumental pada keseimbangan kerja keluarga dan kesejahteraan subjektif pemilik usaha kecil dan menengah (UKM) di Perancis (Leung et al, 2020). Adapun penelitian ini bertujuan untuk mengetahui peran keseimbangan kehidupan kerja dan dukungan sosial pada kesejahteraan subjektif, khususnya pada latar guru SLB yang belum pernah diteliti sebelumnya.

\section{Metode}

Penelitian ini menggunakan metode pendekatan kuantitatif dengan dua variabel bebas dan satu variabel tergantung. Variabel bebas dalam penelitian ini adalah keseimbangan kehidupan kerja dan dukungan sosial. Adapun variabel tergantungnya adalah kesejahteraan subjektif. Pengambilan sampel pada penelitian ini menggunakan teknik simple random sampling. Jumlah sampel yang digunakan adalah 50 guru dari populasi 144 guru. Sampel penelitian adalah guru Sekolah Luar Biasa (SLB) yang berada di wilayah Kabupaten Sleman.

Penelitian dilakukan dengan menyebar 22 butir skala kesejahteraan subjektif yang disusun berdasarkan konsep dari Diener (2009) dengan nilai Alpha Cronbach .889. Kemudian, skala keseimbangan kehidupan kerja memiliki 19 butir yang disusun berdasarkan konsep dari Fisher et al. (2009) dengan nilai Alpha Cronbach .827. Terakhir, skala dukungan sosial yang memiliki 32 butir yang disusun berdasarkan konsep dari Sarafino dan Smith (2011) dengan nilai Alpha Cronbach .813. Penelitian dilakukan di beberapa SLB yang terdapat di wilayah kabupaten Sleman, yaitu SLB “A”, SLB “B”, SLB “C”, dan SLB “D”.

\section{Hasil}

Data yang disajikan dalam penelitian ini memberikan gambaran secara umum mengenai data yang diperoleh di lapangan. Deskripsi variabel penelitian dapat dilihat dari rerata hipotetik dan rerata empirik serta deskripsi berdasarkan model distribusi normal. Setiap skor rerata empirik yang lebih tinggi daripada skor rerata hipotetik, secara signifikan dapat dianggap sebagai indikator tingginya keadaan kelompok subjek pada 
variabel yang diteliti. Sebaliknya, setiap skor rerata empirik yang lebih rendah daripada skor rerata hipotetik, secara signifikan dapat dianggap sebagai indikator rendahnya keadaan kelompok subjek pada variabel yang diteliti. Hasil perbandingan rerata empirik dan rerata hipotetik dari masing-masing variabel dapat dilihat pada tabel di bawah ini.

\section{Tabel 1}

Skor Empirik dan Hipotetik

\begin{tabular}{cccccccccc}
\hline \multirow{2}{*}{ Variabel } & Jumlah & \multicolumn{4}{c}{ Skor Empirik } & \multicolumn{4}{c}{ Skor Hipotetik } \\
\cline { 2 - 10 } & Butir & Min & Maks & $M$ & $S D$ & Min & Maks & $M$ & $S D$ \\
\hline $\mathrm{X}_{1}$ & 19 & 41 & 76 & 60.41 & 6.772 & 19 & 76 & 47.5 & 9.5 \\
$\mathrm{X}_{2}$ & 32 & 61 & 96 & 82.05 & 6.877 & 32 & 128 & 80 & 16 \\
$\mathrm{Y}$ & 20 & 38 & 80 & 55.98 & 9.178 & 20 & 80 & 50 & 10
\end{tabular}

Catatan. $\mathrm{Y}=$ kesejahteraan subjektif; $\mathrm{X}_{1}=$ keseimbangan kehidupan kerja; $\mathrm{X}_{2}=$ dukungan sosial.

Deskripsi data di atas dapat digunakan untuk melakukan kategorisasi pada ketiga variabel penelitian. Kategorisasi pada masing-masing variabel dengan menetapkan kriteria kategori yang didasari oleh asumsi bahwa skor subjek merupakan estimasi dalam populasi dan skor subjek dalam populasi terdistribusi secara normal menurut kurva normal standar (Azwar, 2013).

\section{Kesejahteraan subjektif}

Setelah diketahui nilai statistik dari variabel kesejahteraan subjektif, selanjutnya data dikategorikan menjadi tiga kategori, yaitu rendah, sedang, dan tinggi. Adapun norma yang digunakan adalah kategorisasi rendah $(\mathrm{X}<[M-1.0 S D])$, kategorisasi sedang $([M-1.0 S D] \leq \mathrm{X} \leq M)$, dan kategorisasi tinggi $(M<\mathrm{X} \leq[M+1.0$ $S D$ ]) (Azwar, 2010). Tujuan kategorisasi ini adalah menempatkan individu dalam kelompok-kelompok yang terpisah secara berjenjang menurut suatu kontinum berdasar atribut yang diukur.

Tabel 2

Distribusi Frekuensi Kesejahteraan Subjektif Berdasarkan Data Empirik

\begin{tabular}{lcccc}
\hline \multicolumn{1}{c}{ Variabel } & Interval & $n$ & $\%$ & Kategorisasi \\
\hline \multirow{2}{*}{ Kesejahteraan } & $X<46$ & 8 & 16 & Rendah \\
subjektif & $47 \leq X<66$ & 33 & 66 & Sedang \\
$N$ & $\leq X<$ & 9 & 18 & Tinggi \\
$N$ & & 50 & $100 \%$ & \\
\hline
\end{tabular}

Berdasarkan Tabel 2, diperoleh distribusi frekuensi data kesejahteraan subjektif berdasarkan data empirik, yaitu sebanyak sembilan guru (18\%) berada pada kategori tinggi,
33 guru (66\%) berada pada kategori sedang, dan delapan guru (16\%) berada pada kategori rendah. Hal ini menunjukan bahwa kesejahteraan subjektif subjek penelitian tergolong sedang. 


\section{Keseimbangan kehidupan kerja}

Setelah diketahui nilai statistik dari variabel keseimbangan kehidupan kerja, selanjutnya data dikategorikan menjadi tiga kategori, yaitu rendah, sedang, dan tinggi.
Tujuan kategorisasi ini adalah menempatkan individu dalam kelompokkelompok yang terpisah secara berjenjang menurut suatu kontinum berdasarkan atribut yang diukur.

\section{Tabel 3}

Distribusi Frekuensi Keseimbangan Kehidupan Kerja Berdasarkan Data Empirik

\begin{tabular}{lcccc}
\hline \multicolumn{1}{c}{ Variabel } & Interval & $n$ & $\%$ & Kategorisasi \\
\hline \multirow{2}{*}{ Keseimbangan } & $X<X<54$ & 5 & 10 & Rendah \\
kehidupan kerja & $54 \leq X<67$ & 35 & 70 & Sedang \\
$N$ & $X \geq X \geq 67$ & 10 & 20 & Tinggi \\
$N$ & & 50 & 100 & \\
\hline
\end{tabular}

Berdasarkan tabel di atas, diperoleh distribusi frekuensi data keseimbangan kehidupan kerja, yaitu sebanyak 10 guru (20\%) berapa pada kategori tinggi, 35 guru $(70 \%)$ berada pada kategori sedang, dan lima guru (10\%) berada pada kategori rendah. Hal ini menunjukan bahwa keseimbangan kehidupan kerja subjek penelitian tergolong sedang.
Setelah diketahui nilai statistik dari variabel dukungan sosial, selanjutnya data dikategorikan menjadi tiga kategori, yaitu rendah, sedang, dan tinggi. Tujuan kategorisasi ini adalah menempatkan individu dalam kelompok-kelompok yang terpisah secara berjenjang menurut suatu kontinum berdasarkan atribut yang diukur.

\section{Dukungan sosial}

\section{Tabel 4}

Distribusi Frekuensi Dukungan Sosial Berdasarkan Data Empirik

\begin{tabular}{ccccc}
\hline Variabel & Interval & $n$ & $\%$ & Kategorisasi \\
\hline \multirow{3}{*}{ Dukungan Sosial } & $X<X<73$ & 6 & 12 & Rendah \\
& $73 \leq X<89$ & 38 & 76 & Sedang \\
$N$ & $X \geq 89$ & 6 & 12 & Tinggi \\
\hline
\end{tabular}

Berdasarkan Tabel 4, diperoleh distribusi frekuensi data dukungan sosial, yaitu sebanyak enam guru (12\%) berada pada kategori tinggi, 38 guru (76\%) berada pada kategori sedang, dan enam guru (12\%) berada pada kategori rendah. Hal ini menunjukan bahwa dukungan sosial subjek penelitian tergolong sedang. 


\section{Tabel 5}

Hasil Uji Analisis Regresi Dua Prediktor

\begin{tabular}{ccc}
\hline Variabel & $R$ & $R^{2}$ \\
\hline Dukungan sosial * Keseimbangan kehidupan kerja $^{*} .624^{\mathrm{a}}$ & .389 \\
\hline
\end{tabular}

Berdasarkan Tabel 5, dapat keseimbangan kehidupan kerja terhadap disimpulkan bahwa terdapat hubungan yang kesejahteraan subjektif $(R=.624, p=.000[p$ signifikan antara dukungan sosial dan <.01]).

\section{Tabel 6}

Hasil Uji Analisis Korelasi Partial

\begin{tabular}{lccc}
\hline \multicolumn{1}{c}{ Prediktor } & $b$ & $\beta$ & $r$ \\
\hline Keseimbangan Kehidupan Kerja & .656 & .453 & $.453^{* *}$ \\
Dukungan Sosial & .337 & .264 & $.284^{*}$ \\
\hline
\end{tabular}

Catatan. ${ }^{*} \mathrm{p}<.05,{ }^{* *} \mathrm{p}<.01$.

Berdasarkan Tabel 6 dapat disimpulkan bahwa ada hubungan yang sangat signifikan antara keseimbangan kehidupan kerja dan kesejahteraan subjektif tanpa mengontrol dukungan sosial dengan signifikansi sebesar .001 $(p<.01)$ dan koefisien korelasi zero order sebesar .579. Demikian pula terdapat hubungan yang signifikan antara dukungan sosial dan kesejahteraan subjektif tanpa mengontrol keseimbangan kehidupan kerja dengan signifikansi sebesar $.048(p<.05)$ dan koefisien korelasi zero order sebesar .481.

\section{Pembahasan}

Tujuan penelitian ini ialah memeriksa peran antara keseimbangan kehidupan kerja dan dukungan sosial pada kesejahteraan subjektif, khususnya pada latar guru SLB yang belum pernah diteliti sebelumnya. Penelitian ini bertujuan untuk mengetahui peran keseimbangan kehidupan kerja dan dukungan sosial pada kesejahteraan subjektif guru SLB.

Hasil penelitian menunjukkan adanya pengaruh secara parsial antara variabel keseimbangan kehidupan kerja dan dukungan sosial terhadap kesejahteraan subjektif. Hasil penelitian ini sejalan dengan penelitian sebelumnya yang membuktikan bahwa keseimbangan kehidupan kerja dan dukungan sosial berpengaruh positif terhadap kesejahteraan subjektif (Karpagham \& Magesh, 2017; Shams \& Kadow, 2019; Soni \& Bakhru, 2019; YoussefMorgan \& Craig, 2019). Keseimbangan kehidupan kerja mampu mendorong kualitas hidup individu menjadi positif dan pada akhirnya berdampak pada meningkatnya kesejahteraan subjektif individu (Ramos et al., 2015). Individu yang mampu menyeimbangkan perannya dalam 
kehidupan dan pekerjaannya dapat mengurangi munculnya konflik dan stres.

Hasil penelitian di atas sejalan dengan penelitian yang telah dilakukan oleh Gropel Kuhl (2009) bahwa subjek yang telah cukup mendapatkan dan memiliki keseimbangan kehidupan kerja, mereka akan lebih mungkin untuk memenuhi kebutuhan waktu mereka sendiri untuk menyeimbangkan antara kehidupan dan pekerjaan mereka, sehingga mampu menghasilkan peningkatan kesejahteraan subjektif yang baik, dan kesejahteraan subjektif akan diperoleh apabila tujuan hidup bisa tercapai.

Penelitian Haar et al. (2014) menunjukkan bahwa keseimbangan kehidupan kerja secara positif berkaitan dengan kepuasan kerja dan kepuasan hidup. Kepuasan hidup merupakan salah satu aspek dari kesejahteraan subjektif. Dari hasil penelitian tersebut, ditunjukkan bahwa kepuasan kerja, kepuasan hidup, dan keseimbangan kehidupan kerja berkaitan secara positif. Penelitian lain yang sejalan ialah penelitian yang dilakukan oleh Pop (2014) dalam konteks Rumania. Hasil dari penelitian ini menyatakan bahwa keseimbangan kehidupan kerja berkontribusi pada cara mengevaluasi domain kehidupan yang berbeda, seperti hidup dengan baik secara keseluruhan. Tingkat konflik yang rendah dalam keseimbangan kehidupan kerja mengarah pada tingkat kepuasan hidup yang baik, tetapi juga meningkatkan kepuasan keluarga, kepuasan kerja, dan sosial.

Penelitian lain (Jafri \& Batra, 2014) menunjukkan bahwa korelasi dan analisis regresi mengungkapkan pengaruh positif dan signifikan dari keseimbangan kehidupan kerja pada kesejahteraan subjektif. Hal ini sejalan dengan hasil yang didapatkan bahwa keseimbangan kehidupan kerja berpengaruh sangat signifikan terhadap kesejahteraan subjektif.

Keseimbangan yang dirasakan antara pekerjaan dan peran sosial biasanya kondusif untuk kepuasan hidup. Keseimbangan kerjakeluarga ditemukan untuk memprediksi kesejahteraan dan kualitas hidup secara keseluruhan (Greenhaus et al., 2003). Sheldon dan Kasser (1998) menunjukkan bahwa hanya mereka yang dapat mencapai target untuk dapat memenuhi kebutuhan psikologis dan hal penting lainnya yang dapat meningkatkan kesejahteraan. Dari penjelasan tersebut dapat disimpulkan bahwa keseimbangan kehidupan kerja berpengaruh terhadap kesejahteraan subjektif apabila seseorang bisa mencapai target yang diinginkan dan dapat memenuhi kebutuhan psikologis.

Hasil penelitian lain juga menunjukkan adanya pengaruh antara dukungan sosial dan kesejahteraan subjektif. Penelitian Oftafia dan Susandari (2019) menyebutkan bahwa terdapat hubungan positif yang tinggi antara dukungan sosial dan kesejahteraan subjektif aspek kognitif, terdapat hubungan positif yang 
tinggi antara dukungan sosial dan kesejahteraan subjektif aspek afek positif. Demikian pula terdapat hubungan negatif yang tinggi antara dukungan sosial dan kesejahteraan subjektif aspek afek negatif. Aspek dukungan sosial yang memiliki korelasi paling tinggi dengan kesejahteraan subjektif adalah aspek emosi atau dukungan harga diri yang berkorelasi tinggi dengan kesejahteraan subjektif, baik pada aspek kognitif, afek positif, maupun afek negatif.

Penelitian Lutfiyah (2017) menunjukkan adanya hubungan antara dukungan sosial dan kepuasan hidup dengan afek positif, dan tidak terdapat hubungan antara dukungan sosial dan afek negatif pada anak jalanan di wilayah Depok. Hasil analisis menunjukkan bahwa dukungan sosial terhadap kepuasan hidup dengan afek positif berada pada kategori tinggi, sementara afek negatif yang dimiliki berada pada kategori sedang.

Sumbangan efektifyang didapat dari hasil penelitian ini menunjukkan bahwa variabel keseimbangan kehidupan kerja dan dukungan sosial memberikan sumbangan efektif sebesar $38.9 \%\left(R^{2}=.389\right)$. Hal ini menunjukkan adanya faktor lain di luar keseimbangan kehidupan kerja sebesar $61.1 \%$ yang dapat memengaruhi kesejahteraan subjektif. Compton (2005) merangkum pandangan para ahli (Argyle, 1987; Diener et al, 1999; Myers, 1992) mengenai faktor lain yang dapat memengaruhi kesejahteraan subjektif, yaitu: harga diri, kontrol diri, ekstraversi, optimis, relasi sosial positif, serta memiliki arti dan tujuan dalam hidup. Adapun untuk masing-masing variabel, yakni sumbangan efektif variabel keseimbangan kehidupan kerja terhadap kesejahteraan subjektif sebesar 26.23\%. Sedangkan sumbangan efektif variabel dukungan sosial terhadap kesejahteraan subjektif sebesar $12.70 \%$. Artinya variabel dukungan sosial memiliki sumbangan efektif lebih besar dibandingkan variabel keseimbangan kehidupan kerja terhadap kesejahteraan subjektif.

Adapun keterbatasan penelitian ini antara lain, penelitian ini hanya meliputi para guru SLB yang secara khusus mendampingi anak dengan autisme saja. Padahal jenis siswa berkebutuhan khusus memiliki kebutuhan yang beragam. Pada penelitian ini, peneliti tidak melakukan validasi konstruk melalui perbandingan instrumen yang digunakan dengan alat ukur lain yang telah mapan.

\section{Simpulan}

Berdasarkan hasil penelitian ini, dapat ditarik beberapa simpulan. Pertama, terdapat pengaruh yang sangat signifikan antara keseimbangan kehidupan kerja dan dukungan sosial terhadap kesejahteraan subjektif guru SLB. Kedua, terdapat pengaruh yang sangat signifikan antara keseimbangan kehidupan kerja terhadap kesejahteraan subjektif guru SLB. Ketiga, terdapat pengaruh yang signifikan antara dukungan sosial terhadap kesejahteraan subjektif guru SLB. Pengaruh-pengaruh 
tersebut membuktikan pentingnya keseimbangan kehidupan kerja dan dukungan sosial dalam dunia kerja, khususnya profesi sebagai seorang guru dalam meraih rasa bahagia atau kesejahteraan subjektif (subjective well being).

\section{Saran}

Adapun saran bagi peneliti selanjutnya, yakni agar jangkauan penelitian bisa lebih luas, tidak hanya pada guru SLB yang secara khusus mendampingi anak autis, namun juga guru SLB lain yang mendampingi $\mathrm{ABK}$ secara umum, seperti: sindrom Down, cerebal palsy, dan lainlain. Selain itu, diperlukan adanya uji validasi konstruk jika peneliti menyusun sendiri instrumen penelitiannya. Terakhir, diperlukan pula jumlah sampel yang lebih representatif baik dari jumlah maupun kriteria jenis ABK.

\section{Referensi}

Agustin, K., \& Afriyeni, N. (2016). Pengaruh self efficacy terhadap subjective well-being pada guru SLB di kota Padang. Jurnal RAP UNP, 7(1), 36-43. https://doi.org/https:/ /doi.org/10.24036/rapun.v7i1.6605

Annink, A. (2017). From social support to capabilities for the work-life balance of independent professionals. Journal of Management \& Organization, 23(2), 258276.https://doi.org/10.1017/jmo.2016.53

Ardianingsih, F., Mahmudah, S., \& Rianto, E. (2017). Peran guru dalam implementasi Kurikulum 2013 pendidikan khusus pada SLB di Sidoarjo. Jurnal Pendidikan (Teori Dan Praktik), 2(1), 21-30. https:/ /doi.org/https://doi.org/10.26740/ jp.v2n1.p21-30

Argyle, M. (1987). The psychology of happiness. Methuen.
Azwar, S. (2013). Penyusunan skala psikologi. Pustaka Pelajar.

Brandstätter, H., \& Opp, K. D. (2014). Personality traits ("Big Five") and the propensity to political protest: Alternative models. Political Psychology, 35(4), 515-537. https://doi.org/https:/ /doi.org/10.1111/pops.12043

Carr, A. (2011). Positive psychology/: The science of happines and human strengths.

Cintantya, D., \& Nurtjahjanti, H. (2018). Hubungan antara work-life balance dengan subjective well-being pada sopir taksi PT. Express Trasindo Utama TBK di Jakarta. Jurnal Empati, 7(1), 339-334. https://ejournal3.undip.ac.id / index.php/empati/article/view/20246/ 19098

Compton, W. C. (2005). Introduction to positive psychology. Malloy Incor-porated.

Diener, E. (2009). The science of well-being the collected works of Ed Diener. Springer.

Diener, E., Suh, E. M., Lucas, R. E., \& Smith, H. L. (1999). Subjective well-being: Three decades of progress. Psychological Bulletin, 125(2), 276. https://doi.org/ 10.1037/0033-2909.125.2.276

Efendi, R. (2005). Guru SLB dan peranannya. Rineka Cipta.

Firmansyah, I., \& Widuri, E. L. (2014). Subjective well-being pada guru Sekolah Luar Biasa (SLB). EMPATHY, 2(1), 1-8. http://journal.uad.ac.id/index.php/ EMPATHY/article/view/3006

Fisher, G. G., Bulger, C. A., \& Smith, C. S. (2009). Beyond work and family: a measure of work/nonwork interference and enhancement. Journal of Occupational Health Psychology, 14(2), 441-456. https://doi.org/https://doi.org/ $10.1037 / \mathrm{a} 0016737$

Greenhaus, J. H., Collins, K. M., \& Shaw, J. D. (2003). The relation between workfamily balance and quality of life. Journal of Vocational Behavior, 63(3), 510-531. 
https: //doi.org/https://doi.org/ 10.1016/S0001-8791(02)00042-8

Gröpel, P., \& Kuhl, J. (2009). Work life balance and subjective well-being: the mediating role of need fulfilment. British Journal of Psychology, 100(2), 365-375. https:// doi.org/10.1348/000712608X337797

Haar, J., Russo, M., Sunyer, A., \& Ollier, M. A. (2014). Outcomes of work-life balance on job satisfaction, life satisfaction and mental health: A study across seven cultures. Journal of Vocational Behavior, 85(3), 361-373. https://doi.org/ 10.1016/j.jvb.2014.08.010

Hutapea, B., \& Budiarto, Y. (2016). Aplikasi psikologi positif untuk meningkatkan wellbeing guru-guru Bruderan Purwokerto. Jurnal Pemberdayaan Masyarakat, 3(1), 25-38.

Jafri, H., \& Batra, M. (2014). Work life balance and subjective well-being: Role of social support and psychological detachment. MERC Global's Internasional Journal of Management, 2(4), 133-150. https:// ijm.mercglobal.org/abstractm83.html

Karpagham, C., \& Magesh, R. (2017). Work life balance of employees working in organized manufacturing sector: A study with specific reference to Chennai, Tamil Nadu, India. Asian Journal of Research in Social Sciences and Humanities, 7(2), 919-935. https://doi.org/https:// d o i . org / $10.5958 / 2249$ 7315.2017.00140.X

Kurniawan, W., Mujahid, D. R., \& Usman, Y. (2018). Apakah sastra mampu menurunkan cognitive closure pada narapidana terorisme di Indonesia? Jurnal Psikologi Sosial, 16(2), 114-124. https://doi.org/10.7454/jps.2018.11

Leung, Y. K., Mukerjee, J., \& Thurik, R. (2020). The role of family support in work-family balance and subjective well-being of SME owners. Journal of Small Business Management, 58(1), 130-163. https:// d o i . o r g / 10 . 1080 / 00472778.2019 .1659675
Lutfiyah, N. (2017). Hubungan antara dukungan sosial dengan subjective well being pada anak jalanan di wilayah Depok. Jurnal Psikologi Universitas Gunadharma, 10(2), 152-159. https:// ejournal.gunadarma.ac.id/index.php/ psiko/article/view/1784

Marsidi, A. (2007). Profesi keguruan pendidikan luar biasa. Departemen Pendidikan Nasional.

Myers, D. (1992). The pursuit of happiness: Discovering the pathway to fulfillment, well-being, and enduring personal joy. Avon Books.

Oftafia, S., \& Susandari. (2019). Hubungan dukungan sosial dengan subjective well beingpada anggota komunitas hijrah. SPeSIA UNISBA Prosiding Psikologi, 5(1), 158-162. http:// karyailmiah.unisba.ac.id/index.php/ psikologi

Pop, C. E. (2014). Work life balance and subjective well-being in Romania. Journal of Community Positive Practices, 14(4), 34-49. http://www.jppc.ro/ index.php/jppc/article/view/256

Ramos, H. M., Francis, F., \& Philipp, R. V. (2015). Work-life balance and quality of life among employees in Malaysia. Journal of Happiness and Development, 1(2), 38-50. https://doi.org/https://doi/10.1080/ 09585192.2014 .899262 .

Sarafino, E. P., \& Smith, T. W. (2011). Health psychology: Biopsychosocial interactions (7th Editio). Wiley.

Shams, K., \& Kadow, A. (2019). The relationship between subjective well-being and work-life balance among labourers in Pakistan. Journal of Family and Economic Issues, 40(4), 681-690. https://doi.org/ https://doi.org/10.1007/s10834-01909631-5

Sheldon, K. M., \& Kasser, T. (1998). Pursuing personal goals: Skills enable progress, but not all progress is beneficial. Personality and Social Psychology Bulletin, 24(12), 
1319-1331. https://doi.org/https:// doi.org/10.1177/01461672982412006

Soni, P., \& Bakhru, K. M. (2019). Understanding triangulated collaboration of work-life balance, personality traits and eudaimonic well-being. Problems and Perspectives in Management, 17(2), 6382. https://doi.org/https://doi.org/ 10.21511/ppm.17(2).2019.05

Supriadi.(2003). Guru di Indonesia. Geranusa Jaya.

Westman, M., Brough, P., \& Kalliath, T. (2009). Expert commentary on work-life balance and crossover of emotions and experiences: Theoretical and practice advancements. Journal of Organizational
Behavior, 30(5), 587-595. https:// doi.org/https://doi.org/10.1002/job.616

Youssef-Morgan, C. M., \& Craig, L. (2019). Work-life balance, stress and well-being: moderating effects of psychological capital. In R. J. Burke \& A. M. Richardsen (Eds.), Creating Psychologically Healthy Workplaces (pp. 269-385). Edward Elgar Publishing. https://doi.org/https:// d o i . o r g / 1 0 . 43337 / 9781788113427.00028

Received 22 February 2020 Revised 18 April 2020 Accepted 30 May 2020 